\title{
Comparative Study of Management of Intrauterine Fetal Death by Misoprostol versus Oxytocin
}

\author{
Lipika Ghosh, ${ }^{1}$ Fatema Binta Islam, ${ }^{2}$ Farjana Maksurat, ${ }^{3}$ Mamata Manjari, ${ }^{4}$ Rowshan Afrooz ${ }^{5}$
}

\begin{abstract}
Background \& objective: Management of pregnancy with intrauterine fetal death (IUFD) is always puzzling to the obstetricians and mental agony to the patients. Intravenous oxytocin infusion was previously practiced for termination of pregnancy with IUFD. But recently misoprostol is claimed to be better than oxytocin in terms of its efficacy and safety. This prospective study was carried out to find which of these two drugs is suitable for termination of pregnancy with IUFD.

Methods: Based on predefined criteria, a total of 100 singleton pregnant women with gestational age more than 22 weeks, ultrasonographically confirmed as having dead fetus in utero were included in the study and were randomly assigned to vaginal Misoprostol and Oxytocin infusion groups. The outcome was evaluated in terms of time required for induction of labor, induction to delivery time and complications encountered by each group.

Result: The overall time required for induction to delivery was significantly shorter in Misoprostol group than that in Oxytocin group irrespective of their Bishop's score $(p<0.001)$. Even in patients in whom the cervix was unripe (Bishop's score $<6$ ), the mean time required from induction to delivery was much shorter in Misoprostol group ( $p<0.001$ ), but in patients in whom the cervix was ripen, the mean time from induction to delivery in Misoprostol group was shorter, but the difference did not turn to significant $(p=0.079)$. Both nulliparous and multiparous women experienced significantly shorter durations of labor in the Misoprostol group than those in the Oxytocin group ( $p<0.001$ and $p=0.001$ respectively). Complications like hyperstimulation, retained placenta and postpartum hemorrhage all were somewhat higher in Misoprostol group than those in Oxytocin group, but the differences were not statistically significant $(p=0.357, p=0.500$ and $p=0.500$ respectively).

Conclusion: The use of vaginal misoprostol is more effective than intravenous infusion of oxytocin in induction of labor in patients with IUFD. The time required from induction to delivery is appreciably shorter when Misoprostol is used compared to that needed when oxytocin is used.
\end{abstract}

Key words: Induction of labor, misoprostol, oxytocin and intrauterine fetal death (IUFD) etc.

\section{INTRODUCTION:}

Intrauterine fetal death (IUFD) is said when the fetus dies prior to complete expulsion or extraction from the mother at any time after 22 weeks of gestation. The incidence of fetal death beyond 24 weeks is less than $1 \%$ of all pregnancies. Etiology of intrauterine fetal death is not definitely known in 50\% of the cases. Associated conditions include hypertensive diseases of pregnancy, diabetes mellitus, erythroblastosisfetalis, fetal congenital anomalies,

\section{Authors' information:}

'Dr. Lipika Ghosh, Assistant Professor (Obstetrics \& Gynecology), Colonel Malek Medical College, Manikganj

${ }^{2}$ Dr. Fatema Binta Islam, Assistant Professor (Obstetrics \& Gynecology), Ad-Din Women's Medical College, Moghbazar, Dhaka.

${ }^{3}$ Dr. Farjana Maksurat, Jr Consultant (Obstetrics \& Gynecology), UHC, Shibalaya, Manikgonj

${ }^{4}$ Dr. Mamata Manjari, Assistant Professor (Obstetrics \& Gynecology), Colonel Malek Medical College,Manikgonj.

${ }^{5}$ Dr. Rowshan Afrooz, Assistant Professor (Obstetrics \& Gynecology), Nightingle Medical College, Dhaka.

Correspondence: Dr. Lipika Ghosh, Phone: +880 1715-029206, E-mail:arabinda@amber.com.bd 
placental insufficiency, maternal and fetal infection, post-maturity, umbilical cord accidents, trauma etc. ${ }^{1}$

Intrauterine fetal death is suspected when mother complains of absence of previously perceived fetal movements. Real-time Ultrasound is the definitive method for diagnosis, as it directly visualizes the fetal heart. In addition to the absence of fetal cardiac activity, other secondary features might be seen: collapse of the fetal skull with overlapping bones, $^{2}$ hydrops, or maceration resulting in unrecognizable fetal mass. Intrafetal gas (within the heart, blood vessels and joints) is another feature associated with IUFD that might limit the quality of real-time images. ${ }^{3}$ Prolonged retention of dead fetus in utero may result in maternal clotting abnormalities, coagulopathies or disseminated intravascular coagulation (DIC), which needs prompt delivery. Management of intrauterine fetal death could be either expectant or delivery as early as possible as determined by discussion between doctor and the patient concerned. If the woman is physically well, her membranes are intact and there is no evidence of pre-eclampsia, infection or bleeding, the risk of expectant management for 48 hours is low. ${ }^{4,5}$

There is a $10 \%$ chance of maternal DIC within 4 weeks from the date of fetal death and an increasing chance thereafter. ${ }^{6}$ If the patient is treated expectantly clotting studies should be repeated weekly. Expectant management usually results in spontaneous labor in the majority (more than $85 \%$ ) of patients within 3 weeks. ${ }^{4}$ If spontaneous labor does not occur, induction of labor could be tried with a) intravenous administration of increasing concentration of oxytocin or, b) orally or vaginally administered misoprostol, or, c) PGE2 gel + Oxytocin or, d) intrauterine catheter + Oxytocin. Of them, vaginal application or oral administration of misoprostol (a synthetic analogue of PGE1) is considered the best \& appropriate drug for developing countries like ours. Misoprostol is a cost-effective drug whereas dinoprostone which was randomly used previously in cervical ripening and induction of labor is very costly and only one dose is not sufficient.

Misoprostol has been shown to be less expensive and more effective than oxytocin in the induction of labor. The use of misoprostol for induction of labor in women with IUFD has been endorsed by NICE. ${ }^{4}$ A randomized controlled trial comparing intravenous oxytocin alone with intravaginal misoprostol (a prostaglandin E1 analogue) for induction of labor in women with an IUFD showed that misoprostol was more effective. ${ }^{7}$ A recent study has confirmed that women receiving intravaginal misoprostol have a significantly lower caesarean section rate, shortened interval between start of induction to vaginal delivery, a higher incidence of vaginal delivery (about 90\%) within 24 hours of misoprostol application. ${ }^{8}$ Two randomized controlled trials compared oral and vaginal misoprostol. In the first, the mean induction to birth interval was shorter with vaginal use by 7.9 hours $(p<0.05) \&$ there was a reduced need for oxytocin augmentation. ${ }^{9}$ In the other, there was no difference in mean induction to birth interval for gestations of more than 28 weeks. ${ }^{10}$ Recently, in a closely supervised hospital setting with adequate monitoring, oral misoprostol has the potential to induce labor as safely and effectively as its vaginal analogue. ${ }^{11}$ Misoprostol effectively induces labor, with the vaginal route of administration having a faster action than the oral route in equivalent doses. ${ }^{12}$ The present study was, therefore, undertaken to make a comparative evaluation between outcome of induction of labor in pregnant women with IUFD by vaginal misoprostol and oxytocin to find the suitable method for termination of pregnancy with IUFD.

\section{METHODS:}

This prospective study was conducted over a period of 12 months from July 2009 to June 2010 in the Department of Obstetrics \& Gynaecology, Dhaka Medical College Hospital, Dhaka. Singleton pregnant women with history of gestational age $>28$ weeks and recent absence of previously perceived fetal movement, intact membrane with 
no labor pain were provisionally included in the study. Of them who were confirmed as having dead fetus in utero by real-time ultrasonography were finally included in the study. The patients were randomly divided into two groups-Oxytocin group and Misoprostol group. The Oxytocin group received 10 units of oxytocin added to a $500 \mathrm{ml}$ of Hartman's solution if the patients were primigravida and 5 units per $500 \mathrm{ml}$ of Hartman's solution if patients were multigravida. All infusions were started at $15 \mathrm{drop} / \mathrm{min}$, and increasing every 30 minutes by $5 \mathrm{drop} / \mathrm{min}$ till effective uterine contraction was achieved ( 3 to 4 contractions per 10 minutes), or up to a maximum of $60 \mathrm{drop} / \mathrm{min}$. If no effective contractions were noted, a new infusion with double the original dose was reinstituted. If labor was not established within 48 hours of induction, this was regarded as failed induction \& the drug administration was stopped. This also applied in the misoprostol group.

Vaginal examination was done four hours later or as necessary to assess the Bishop's score. The rate, maximum dose and total dose of oxytocin needed were recorded. In the Misoprostol group (Tab Cytomis or Isovent) "1/4 Tab Misoprostol" (50 $\mu \mathrm{g})$ was applied on the vagina and the dose was doubled every 6 hours till effective contractions were achieved. The tablet was wetted with a drop of water for injection and was inserted in the posterior vaginal fornix using a Cusco's speculum and a wooden spatula. Following medication, maternal condition regarding temperature, pulse, blood pressure, uterine contraction, postpartum haemorrhage (PPH) was observed closely. Cervical score was reassessed after 4 hours or as necessary. Majority of patients was delivered within 24 hours. If labor was not established within 24 hours of induction, this was regarded as failed induction and the trial was stopped. The outcome was evaluated in terms of time required for induction of labor, induction to delivery time and complications (like hyperstimulation, retained placenta and PPH) encountered by each group. From the very beginning prophylactic antibiotics were given in both groups for prevention of ascending infection. Data were processed and analyzed using software SPSS (Statistical Package for Social Sciences) version 25.0. The test statistics used to analyze the data were descriptive statistics, Chi-square $\left(\chi^{2}\right)$ Test and Student's t-Test. Quantitative data were presented in the form of mean \pm SD and qualitative data as frequency and corresponding percentage. The level of significance was set at 0.05 and $p$-value < 0.05 was considered significant.

\section{RESULTS:}

\section{Baseline characteristics: \\ Demographic characteristics:}

Majority of the patients in either group was found in the age range of $25-29$ years. The patients in the Oxytocin group was comparatively young (mean age: 24.4 years) than those in the Misoprostol group (mean age: 28.7 years), although the difference was not statistically significant $(p=0.147)$. Housewives were predominant in both Oxytocin (64\%) and Misoprostol group (72\%) with no significant intergroup difference $(p=0.391)$ (Table I).

\section{Obstetric characteristics:}

Nullipara was predominant in both groups ( $74 \%$ in Oxytocin and $66 \%$ in Misoprostol group), but the difference between the groups was not statistically significant $(p=0.382)$. Nearly one-third $(30.0 \%)$ of the Oxytocin group patients and $34 \%$ of Misoprostol group patients received antenatal care regularly and rest of the respective groups did not receive ANC. The difference between the groups was not statistically significant $(p=0.668)$ (Table II).

\section{Medical illnesses:}

Seven $(14.0 \%)$ patients in the Oxytocin group and $5(10.0 \%)$ patients in the Misoprostol group had hypertension ( $p=0.538$ ). Diabetes was reported to be 18 and $14 \%$ in Oxytocin and Misoprostol groups respectively $(p=0.585)$. Anemia was invariably present in both groups (Table III). 


\begin{tabular}{|c|c|c|c|}
\hline \multirow{2}{*}{ Characteristics } & \multicolumn{2}{|c|}{ Group } & \multirow{2}{*}{$\mathrm{p}$-value } \\
\hline & $\begin{array}{l}\text { Oxytocin } \\
(n=50)\end{array}$ & $\begin{array}{l}\text { Misoprostol } \\
(n=50)\end{array}$ & \\
\hline \multicolumn{4}{|l|}{ Age (years)* } \\
\hline$<20$ & $1(2.0)$ & $2(4.0)$ & \\
\hline $20-25$ & $10(20.0)$ & $6(12.0)$ & \\
\hline $25-30$ & $22(44.0)$ & $20(40.0)$ & \\
\hline $30-35$ & $15(30.0)$ & 18(36.0) & \\
\hline$\geq 35$ & $2(4.0)$ & $4(8.0)$ & \\
\hline Mean \pm SD\# & $24.4 \pm 4.9$ & $28.7 \pm 5.0$ & 0.147 \\
\hline \multicolumn{4}{|l|}{ Occupation* } \\
\hline Housewife & $32(64.0)$ & $36(72.0)$ & \multirow{2}{*}{0.391} \\
\hline Service holder & $18(36.0)$ & $14(28.0)$ & \\
\hline
\end{tabular}

Figures in the parentheses indicate corresponding \%; \#Data were analyzed using Unpaired t-Test and were presented as mean \pm SD.

${ }^{*}$ Chi-squared Test $\left(\chi^{2}\right)$ was done to analyze the data.

\begin{tabular}{|c|c|c|c|}
\hline \multirow{2}{*}{$\begin{array}{l}\text { Obstetric } \\
\text { characteristics* }\end{array}$} & \multicolumn{2}{|c|}{ Group } & \multirow[b]{2}{*}{$\mathrm{p}$-value } \\
\hline & $\begin{array}{l}\text { Oxytocin } \\
(n=50)\end{array}$ & $\begin{array}{l}\text { Misoprostol } \\
\quad(n=50)\end{array}$ & \\
\hline \multicolumn{4}{|l|}{ Parity } \\
\hline Nullipara & $37(74.0)$ & $33(66.0)$ & \multirow{2}{*}{0.382} \\
\hline Multipara & $13(26.0)$ & $17(34.0)$ & \\
\hline \multicolumn{4}{|c|}{ Antenatal care (ANC) } \\
\hline Received & $15(30.0)$ & $17(34.0)$ & \multirow{2}{*}{0.668} \\
\hline Not received & $35(70.0)$ & $33(66.0)$ & \\
\hline
\end{tabular}

Figures in the parentheses indicate corresponding \%; *Chi-squared Test $\left(\chi^{2}\right)$ was done to analyze the data.

\begin{tabular}{|c|c|c|c|}
\hline \multirow{2}{*}{$\begin{array}{l}\text { History medical } \\
\text { illness* }\end{array}$} & \multicolumn{2}{|c|}{ Group } & \multirow[b]{2}{*}{$\mathrm{p}$-value } \\
\hline & $\begin{array}{l}\text { Oxytocin } \\
(n=50)\end{array}$ & $\begin{array}{c}\text { Misoprostol } \\
(n=50)\end{array}$ & \\
\hline Hypertension & $7(14.0)$ & $5(10.0)$ & 0.538 \\
\hline Diabetes mellitus & $9(18.0)$ & $7(14.0)$ & 0.585 \\
\hline Anemia & $50(100.0)$ & $50(100.0)$ & 0.987 \\
\hline
\end{tabular}

Figures in the parentheses indicate corresponding \%; ${ }^{*}$ Chi-squared Test $\left(\chi^{2}\right)$ was done to analyze the data.

\section{Outcome:}

\section{Duration of labor}

In both nulliparous and multiparous women, the mean durations of labor were significantly shorter in the Misoprostol group than those in Oxytocin group $(p<0.001$ and $p=0.001$ respectively) (Table IV).

\section{Induction to delivery interval:}

The mean time from induction to delivery was dramatically reduced in Misoprostol group than that in Oxytocin group irrespective of their Bishop's score $(p<0.001)$. In patients with unripe cervix (Bishop's score $<6)$, the mean interval between induction to delivery was significantly shorter $(p<0.001)$. But in patients with ripen cervix (Bishop's score of $\geq 6$ ), the mean time from induction to delivery was although relatively shorter, it did not reach the level significance $(p=0.079)$ (Table V).

\section{Complications:}

Complications like hyperstimulation, retained placenta and postpartum hemorrhage all were somewhat higher in Misoprostol group than those in Oxytocin group, but the differences were not statistically significant $(p=0.357, p=0.500$ and $\mathrm{p}=0.500$ respectively) (Table VI).

Table IV. Comparison of duration labor between the study groups

\begin{tabular}{lccc}
$\begin{array}{l}\text { Duration of } \\
\text { labor (hours) }\end{array}$ & \multicolumn{2}{c}{ Group } & p-value \\
\cline { 2 - 3 } & $\begin{array}{c}\text { Oxytocin } \\
(\mathrm{n}=50)\end{array}$ & $\begin{array}{c}\text { Misoprostol } \\
(\mathrm{n}=50)\end{array}$ & -val \\
Nulliparous & $10.1 \pm 5.6$ & $5.3 \pm 2.5$ & $<0.001$ \\
Multiparous & $5.3 \pm 4.1$ & $3.0 \pm 1.7$ & 0.001
\end{tabular}

\#Data were analyzed using Unpaired t-Test and were presented as mean \pm SD.

\begin{tabular}{|c|c|c|c|}
\hline \multirow[b]{2}{*}{$\begin{array}{l}\text { Induction to } \\
\text { delivery (hours) }\end{array}$} & \multicolumn{2}{|c|}{ Group } & \multirow[b]{2}{*}{ p-value } \\
\hline & $\begin{array}{l}\text { Oxytocin } \\
(n=50)\end{array}$ & $\begin{array}{l}\text { Misoprostol } \\
(n=50)\end{array}$ & \\
\hline All patients & $23.3 \pm 6.5$ & $12.4 \pm 3.1$ & $<0.001$ \\
\hline Bishop's score < 6 & $29.8 \pm 7.3$ & $15.9 \pm 3.2$ & $<0.001$ \\
\hline Bishop's score $\geq 6$ & $9.0 \pm 3.8$ & $7.9 \pm 2.2$ & 0.079 \\
\hline
\end{tabular}

Table VI. Comparison of complications between the study groups

\begin{tabular}{lccc} 
& \multicolumn{2}{c}{ Group } & \\
\cline { 2 - 3 } Complications* & $\begin{array}{c}\text { Oxytocin } \\
(\mathrm{n}=50)\end{array}$ & $\begin{array}{c}\text { Misoprostol } \\
(\mathrm{n}=50)\end{array}$ & p-value \\
Hyperstimulation & $3(6.0)$ & $5(10.0)$ & 0.357 \\
Retained placenta & $1(2.0)$ & $2(4.0)$ & 0.500 \\
Postpartum hemorrhage & $1(2.0)$ & $2(4.0)$ & 0.500
\end{tabular}

Figures in the parentheses indicate corresponding \%; ${ }^{*}$ Chi-squared Test $\left(\chi^{2}\right)$ was done to analyze the data. 


\section{DISCUSSION:}

The present study demonstrated that use of vaginal misoprostol is more effective than intravenous infusion of oxytocin in induction of labor in patients with IUFD. The costs involved and times required from induction to delivery were remarkably reduced as compared to induction using oxytocin infusion. The drug was easily stored at room temperature and was easy to administer. The study also showed that small doses of vaginal misoprostol effectively induce labor and they are safe for the mothers, although complications like hyperstimulation, retained placenta \& postpartum haemorrhage were more in the misoprostol group. These findings fairly compare with findings of Sanchez-Ramos et al ${ }^{13}$.

The mean duration of labor was significantly shorter in the Misoprostol group than that in Oxytocin group irrespective of their parity $(p<0.001$ and $p=0.001$ respectively). When the duration of labor in nulliparous and multiparous women was analyzed separately, the overall duration of labor was significantly shorter in the Misoprostol group compared to that in the Oxytocin group (5.3 vs. 10.1 hours, $p<0.001)$. Ngai et al ${ }^{14}$ observed that $60 \%$ women in the misoprostol group required a single dose $(100 \mu \mathrm{g})$, while the remaining $40 \%$ required a second dose $(200 \mu \mathrm{g})$. The duration of labor was significantly shorter in the misoprostol group compared to Oxytocin group $(p=0.004)$. A significant difference was also seen in both the first and the second stages of labor between the misoprostol and oxytocin group (5.0 vs. 9.6 hours, $\mathrm{p}=0.03$ and 0.6 vs. 1.2 hours, $\mathrm{p}=0.01$ respectively). Although their induction-to-delivery interval in the nulliparous women was shorter in the misoprostol group, this difference did not reach statistical significance. In contrast, Nakintu ${ }^{7}$ found no significant difference in induction to delivery time between the misoprostol and oxytocin group ( 8.5 vs. 10.5 hours, $p=0.60$ ).

In the current series the mean time from induction to delivery was drastically shorter in Misoprostol group than that in Oxytocin group irrespective of their Bishop's score $(p<0.001)$. Even in patients in whom the cervix was unripe (Bishop's score $<6$ ), the mean time required from induction to delivery was staggeringly shorter in Misoprostol group ( $p<$ 0.001 ), but in patients in whom the cervix was ripen, the mean time from induction to delivery in Misoprostol group was shorter, but the difference did not turn to significant $(p=0.079)$, which are consistent with the findings of Nakintu. ${ }^{7}$

\section{CONCLUSION:}

From the findings of the study it can stated that vaginal misoprostol is more effective than intravenous infusion of oxytocin in induction of labor in patients with IUFD. The costs involved and times required from induction to delivery were remarkably shorter as compared to induction using oxytocin infusion. As misoprostol is cheaper than oxytocin in cervical ripening and induction of labor in patients with intrauterine fetal death, its use for induction of labor particularly in intrauterine fetal death will be cost-effective in the management of this obstetric complication. The drug can also be accessed and tried in the lower levels of health system to manage the condition to avoid undue delays and referrals to large hospitals.

\section{REFERENCES:}

1. Confidential Enquiry into Maternal and Child Health (CEMACH). Perinatal Mortality 2007: United Kingdom. CEMACH:London 2009 [http://www.cmace.org.uk/ getattachment/1d2c0ebc-d2aa-4131-98ed-56bf8 269 e529/PerinatalMortality-2007.aspx].

2. Zeit RM. Sonographic demonstration of fetal death in the absence of radiographic abnormality. Obstet Gynecol 1976;48(1 Suppl):49S-52S.

3. Weinstein BJ, Platt LD. The ultrasonic appearance of intravascular gas in fetal death. J Ultrasound Med $1983 ; 2: 451-4$.

4. National Institute for Health and Clinical Excellence. Clinical guideline no. 70: Induction of labour. London: National Institute for Health and Clinical Excellence; 2008[http://www.nice.org.uk/nicemedia/pdf/CG070NI CEGuideline.pdf].

5. Silver RM. Fetal death. Obstet Gynecol 2007; 109: 153-67. 
6. Parasnis H, Raje B, Hinduja IN. Relevance of plasma fibrinogen estimation in obstetric complications. J Postgrad Med 1992;38:183-5.

7. Nakintu N. A comparative study of vaginal misoprostol and intravenous oxytocin for induction of labour in women with intra uterine fetal death in Mulago Hospital, Uganda. Afr Health Sci 2001;1:55-9.

8. Wagaarachchi PT, Ashok PW, Narvekar NN, Smith NC, Templeton A. Medical management of late intrauterine death using a combination of mifepristone and misoprostol. BJOG 2002;109:443-7.

9. Nyende L, Towobola OA, Mabina MH. Comparison of vaginal and oral misoprostol, for the induction of labour in women with intra-uterine foetal death. East Afr Med J 2004;81:179-82.

10. Chittacharoen A, Herabutya Y, Punyavachira P. A randomized trial of oral and vaginal misoprostol to manage delivery in cases of fetal death. Obstet Gynecol 2003;101:70-3.
11. Hall R, Duarte-Gardea M, Harlass F. Oral versus vaginal misoprostol for labor induction. Obstetrics \& Gynecology 2002;99(6):1044-48.

12. Shetty A, Danielian $P$, Templeton A. A comparison of oral and vaginal misoprostol tablets in induction of labour at term. Br J Obstet Gynaecol 2001;108(3):238-43.

13. Sanchez-Ramos L, Chen AH, Kaunitz A, Gaudier FL, Oelke I. Labor Induction With Intravaginal Misoprostol in Term Premature Rupture of Membranes: A Randomized Study. The American Journal of obstetricians and Gynaecologists 1997;89: 909-12.

14. Ngai SW, Chan YM, Lam SW, Lao TT. Labour characteristics and uterine activity: misoprostol compared with oxytocin in women at term with prelabour rupture of the membranes. BJOG 2000;107(2):222-227.//doi.org/10.1111/j.1471-0528. 2000.tb11693. 